RAD Conference Proceedings, vol. 4, pp. 101-105, 2020

ISSN 2466-4626 (online) | DOI: 10.21175/RadProc.2020.21

www.rad-proceedings.org

\title{
CATECHIN HYDRATE DESORPTION FROM NEWLY-SYNTHESIZED CATECHIN-LOADED BIOPOLYMER PARTICLES
}

\author{
Zvezdelina Yaneva*, Donika Ivanova
}

Chemistry Unit, Department of Pharmacology, Animal Physiology and

Physiological Chemistry, Faculty of Veterinary Medicine, Trakia University, Stara Zagora, Bulgaria

\begin{abstract}
The aim of the recent study was to assess the extent of catechin hydrate release from newly synthesized bioflavanol-loaded chitosan-based particles. The biopolymer particles were prepared by a modified ion gelation method. The synthesized biopolymer particles were divided into two series: Series 1 - washed with ethanol and stored in $70 \%$ EtOH at $4^{\circ} \mathrm{C}$, and Series 2 - washed with EtOH, dried and stored at $-18^{\circ} \mathrm{C}$. Both particle series were stable after $72 \mathrm{~h}$ storage. The desorption experiments were conducted by agitation of determined mass of catechin-loaded particles in PBS for $48 \mathrm{~h}$. The maximum efficiency of catechin desorption from series 1 particles in PBS was 91\% in simulated intestinal medium after $48 \mathrm{~h}$. Series 2 catechin-loaded particles exhibited slightly higher desorption extend in PBS. It has to be outlined that the size of series 1 particles significantly decreased, while the dried particles were completely degraded at the end of the experiment.
\end{abstract}

Keywords: Chitosan particles, catechin hydrate, encapsulation, release

\section{INTRODUCTION}

Catechins have been acknowledged as naturally derived biomolecules exhibiting profusive pharmacological and therapeutic activities like antiinflammatory, antimicrobial, antitumor, antiaging, antioxidant, etc. [1-3] This wide array of health effects, however, is significantly hampered due to the poor bioavailability, short half-life, stability issues, short shelf life, sensitivity to oxidation, limited gastrointestinal tract absorption and reduced biological activity of the bioflavanols [4]. Modern scientific studies have recently developed various advanced methodologies to surmount these limitations and to reveal the full therapeutic potential of catechins by modulation of innovative encapsulation technologies and subsequent release studies $[5,6]$.

Chitosan, a naturally originated cationic polymer has been intensively applied for the design and synthesis of drug excipients due to its potential for application in pharmaceutical dosage forms [7]. The significant recent interest in the biopolymer has been provoked as a result of its unique properties: presence of reactive functional groups, gelation capability, high adsorption capacity, biodegradability and biocompatibility, antibacterial, antifungal and antitumor physiological activity [8]. These functional properties provide suitability and extensive pharmaceutical applications such as for the preparation of drug delivery systems (drug conjugate, micro/nanoparticles, hydrogels, emulsions, biodegradable release system, etc.) and for regenerative medicine [7,9-11].
Recent scientific studies propose that biodegradable biopolymer-carriers could release the encapsulated biologically active substances through: enzymatic decomposition due to degradation of ester, amide bonds, or hydrolysis; surface erosion from the exterior towards the interior implying matrix degradation starting at the surface, followed by slow reduction of the microparticle size; bulk erosion associated with water penetration within the biopolymer matrix, followed by homogeneous degradation of the entire matrix [7,12]. The determination of the encapsulation and release mechanism of bioactive compounds requires detailed mass transfer studies associated with assessment of the extent of applicability of various mathematical models [13-16].

The increased search for the design and synthesis of bio-friendly carriers with enhanced bioactivities and sustained release of encapsulated bioflavonoids provoked the present investigations.

The aim of the recent study was to assess the extent of catechin hydrate release from newly synthesized bioflavanol-loaded chitosan-based microparticles.

\section{MATERIALS AND METHODS}

\subsection{Reagents}

Chitosan (medium molecular weight, CAS No.: 9012-76-4), (+)-catechin hydrate $(\mathrm{C} 15 \mathrm{H} 14 \mathrm{O} 6 \cdot \mathrm{xH} 2 \mathrm{O})$ ( $\geq$ 98.0 \%, HPLC, powder) (CAS No.: 225937-10-0), $\mathrm{CH}_{3} \mathrm{COOH}$ (p.a., HPLC), Tween $\AA 80$ (CAS No.:900565-6), glutaraldehyde solution (Grade II, $25 \%$ in $\mathrm{H}_{2} \mathrm{O}$,

“z.yaneva@abv.bg 
Z. Yaneva, and D. Ivanova, Catechin hydrate desorption..., RAD Conf. Proc., vol. 4, 2020, 101-105

CAS No.: 111-30-8), EtOH (p.a. $\geq 99.8$ \%, HPLC), phosphate buffered saline (PBS, P-3813) were supplied by Sigma. Paraffinum perliquidum (Ph. Eur.[0240] was supplied by Chimax Pharma, Bulgaria.

\subsection{Methods}

The chitosan microparticles were synthesized by a modified ion gelation method. $0.1 \mathrm{~g}$ chitosan was dissolved in $2 \% \mathrm{CH}_{3} \mathrm{COOH}$ under magnetic stirring; $25 \mathrm{~mL}$ paraffin and $1 \mathrm{~mL}$ Tween 80 were added to the transparent acidic chitosan solution. Predetermined mass of catechin hydrate was incorporated into the mixture before the cross-linking stage with $5 \%$ glutaraldehyde solution. The obtained biopolymer microparticles were subjected to centrifugation at 5,000 $g$ followed by washing with double distilled water and $70 \% \mathrm{EtOH}$. The synthesized biopolymer particles were divided into two series: Series 1 - washed with ethanol and stored in $70 \% \mathrm{EtOH}$ at $4^{\circ} \mathrm{C}$, and Series 2 - washed with EtOH, dried for $24 \mathrm{~h}$ in hot air oven at $35^{\circ} \mathrm{C}$ and stored at $-18^{\circ} \mathrm{C}$. Both types of particle series were stable after 60 days storage, which was proven by periodical (on the 2, 5, 10, 20, 40 and 60 day) measurements of the size of Series 1 and Series 2 particles and exploration of their morphology under digital microscope.

Desorption experiments were conducted by agitation of predetermined mass of catechin-loaded particles in PBS $(\mathrm{pH}=7.4)$ for $48 \mathrm{~h}$ at $T=37^{\circ} \mathrm{C}$. Samples were taken at predetermined time periods and the desorbed catechin concentration in the liquid phase $\left(C_{\text {des }}, \mu \mathrm{g} / \mathrm{mL}\right)$ was determined by UV/Vis spectrophotometric measurement of the bioflavanol concentration in the liquid phase. UV/Vis spectrophotometric analyses were conducted on DR $5000 \mathrm{UV} / \mathrm{Vis}$ spectrophotometer (Hach Lange, Germany) [17]. The release efficiency ( $E$, \%) was calculated by the formula:

$$
E=\frac{\text { amount of released substance }}{\text { total amount of encapsulated substance }} \cdot 100, \%
$$

The morphological characteristics of the newly synthesized chitosan microparticles were investigated by digital microscopy.

All experiments were carried out in triplicate, and the average values were taken to minimize random error.

\subsection{Mathematical modelling, statistical and error analysis}

Non-linear regression analyses were applied for interpretation of the applicability of the zero-order and Korsmeyer-Peppas kinetics release models to the experimental data.

The statistical and error analyses were conducted by XLStat for Excel.

\section{RESULTS AND DISCUSSION}

\subsection{Morphological study}

The digital microscopic images of chitosan microformulations at three magnifications: 40x, 100x and 400x (Figure 1), proved that the particles characterized with spherical shape, homogeneous surface and approximately uniform size within the range $220-280 \mu \mathrm{m}$.

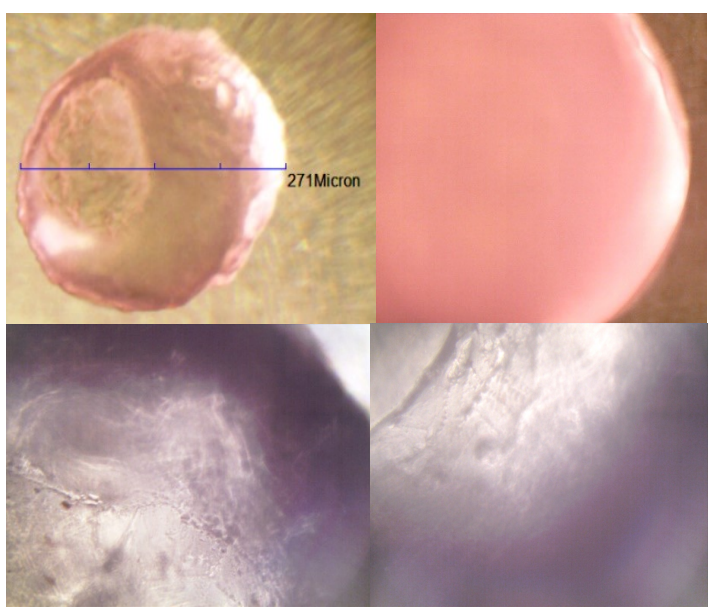

Figure 1. Digital microscopic images of chitosan microparticles at: A. 40x; B. 100x and C. 400x magnification.

\subsection{UV/Vis spectrophotometry}

To determine catechin concentrations in PBS and simulated gastric medium during the desorption experiments, the bioflavanol absorbances at $\lambda=280$ $\mathrm{nm}$ were spectrophotometrically measured. The corresponding calibration catechin hydrate curves in neutral and acidic medium, their characteristic linear equations and regression values $\left(R^{2}\right)$ are presented elsewhere [17].

\subsection{Desorption study}

The aim of the experimental design was to investigate and compare the in vitro release bahaviour of catechin, as well as the stability of the catechinloaded chitosan microparticles under physiological conditions considering their storage conditions.

The desorption experiments with the chitosan microparticles washed in EtOH and stored in $70 \%$ $\mathrm{EtOH}$ at $4^{\circ} \mathrm{C}$, were conducted successively in PBS at $\mathrm{pH}=7.4$ for $48 \mathrm{~h}$, simulating intestinal medium, until equilibrium. The aim of the experimental design was to investigate the in vitro release behaviour of catechin, as well as the stability of the catechin-loaded chitosan microparticles under physiological conditions. The experimental results established maximums extend of $91 \%$ of catechin release from Series 1 particles in PBS after $48 \mathrm{~h}$ (Figure 2). It has to be outlined that the size of series 1 particles significantly decreased. The experimental release kinetics curve (Figure 3) is biphasic with a profile encompassing small initial "burst" region followed by a long-term stage of linear slow release.

With respect to bimodal release curves, recent studies attribute the initial burst effect to adsorbed residual catechin in the superficial zone or the shell surrounding the biopolymer microparticle surface, while the prolonged subsequent zone was due to a 
Z. Yaneva, and D. Ivanova, Catechin hydrate desorption..., RAD Conf. Proc., vol. 4, 2020, 101-105

release from a polyphenol-enriched core [18.19]. In the present study, catechin behavior during the short stage of burst release in alkaline medium up to 90 min was modelled by the Korsmeyer-Peppas kinetics model, while the second prolonged region (up to $48 \mathrm{~h}$ ) of the curve was best correlated with the zero-order model (Figure 3). Both mathematical models characterized with satisfactorily high values of the regression coefficients and low values of the SSE, MSE and RMSE error functions obtained by non-linear regression analyses (Table 1).

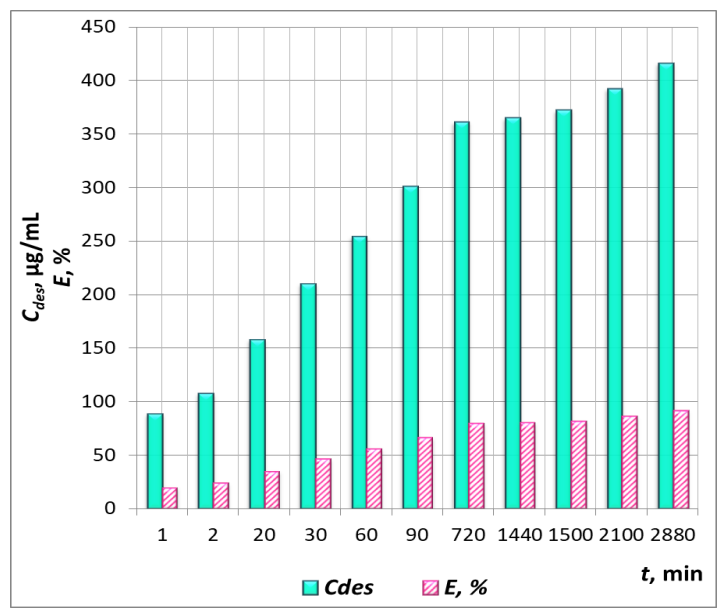

Figure 2. In vitro release efficiency of catechin from Series 1 chitosan microparticles.

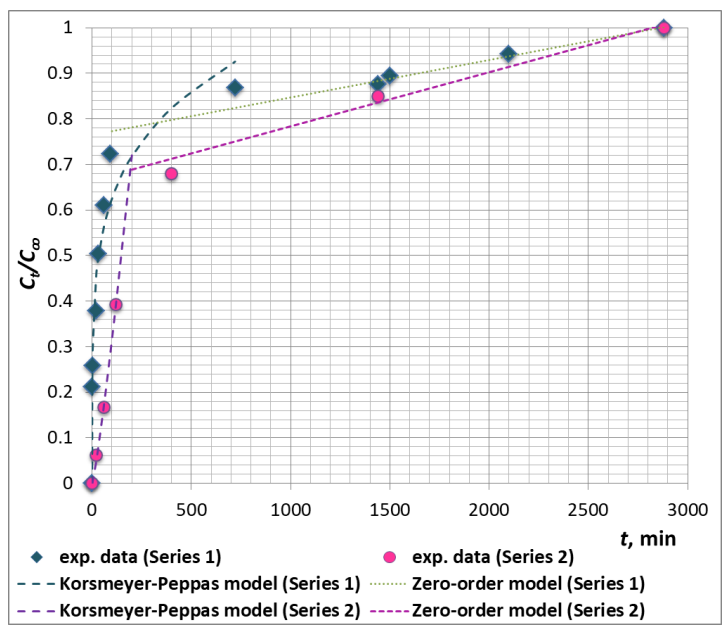

Figure 3. In vitro release experimental and model kinetics curves of catechin from chitosan-based microparticles.

In the Korsmeyer-Peppas equation, the release constant $K$ provides information on the structural characteristics of the carriers, and the exponential parameter $n$ is related to the release mechanism Fickian diffusion, non-Fickian diffusion or Case II trasport. In this respect, as the value of $n$ in the present study is below 0.43 , in the case of spherical biopolymer particles, the burst initial catechin hydrate release is probably due to Fickian diffusion mechanism.
The zero-order model assumes constant-rate timedependent drug release regardless of the concentration of the encapsulated bioactive compound [20]. This mechanism is associated with sustained release. The proven applicability of the zero-order model to the experimental data ascertains sustained release of catechin hydrate from the chitosan-based microparticles for a period of $46.5 \mathrm{~h}$.

Table 1. Values of Korsmeyer-Peppas and zero-order release models parameters and error functions for the system catechin/ microparticles.

\begin{tabular}{|c|c|c|}
\hline $\begin{array}{l}\text { Release } \\
\text { kinetics } \\
\text { model }\end{array}$ & $\begin{array}{l}\text { Korsmeyer- } \\
\text { Peppas model } \\
\frac{C_{t}}{C_{\infty}}=K * t^{n}\end{array}$ & $\frac{C_{t}}{C_{\infty}}=A * t+B$ \\
\hline \multicolumn{3}{|c|}{ Series 1 microparticles } \\
\hline $\begin{array}{l}\text { Model } \\
\text { parameters }\end{array}$ & $\begin{array}{l}K=0.250 \\
n=0.199\end{array}$ & $\begin{array}{l}A=0.765 \\
B=8.22 \times 10^{-5}\end{array}$ \\
\hline $\begin{array}{l}\text { Error } \\
\text { functions }\end{array}$ & $\begin{array}{l}R^{2}=0.956 \\
S S E=0.026 \\
M S E=0.004 \\
R M S E=0.066\end{array}$ & $\begin{array}{l}R^{2}=0.989 \\
S S E=1.046 \times 10^{-4} \\
M S E=5.230 \times 10^{-5} \\
R M S E=7.232 \times 10^{-3}\end{array}$ \\
\hline \multicolumn{3}{|c|}{ Series 2 microparticles } \\
\hline $\begin{array}{l}\text { Model } \\
\text { parameters }\end{array}$ & $\begin{array}{l}K=1.380 \times 10^{-3} \\
n=1.181\end{array}$ & $\begin{array}{l}A=0.665 \\
B=1.188 \times 10^{-4}\end{array}$ \\
\hline $\begin{array}{l}\text { Error } \\
\text { functions }\end{array}$ & $\begin{array}{l}R^{2}=0.999 \\
S S E=2.449 \times 10^{-4} \\
M S E=1.224 \times 10^{-4} \\
R M S E=0.011\end{array}$ & $\begin{array}{l}R^{2}=0.994 \\
S S E=3.20 \times 10^{-4} \\
M S E=3.20 \times 10^{-4} \\
R M S E=1.79 \times 10^{-2}\end{array}$ \\
\hline $\begin{array}{l}\text { Parameters } \\
\text { assignment }\end{array}$ & $\begin{array}{l}C_{t} / C_{\infty}-\text { fractional } \\
\text { permeated drug; } \\
t \text { - time, min; } \\
K \text { - transport } \\
\text { constant, min }{ }^{-1} ; \\
n \text { - transport } \\
\text { exponent, -. }\end{array}$ & $\begin{array}{l}A, B-\text { zero-order } \\
\text { model parameters }\end{array}$ \\
\hline
\end{tabular}

Series 2 catechin-loaded particles, washed in EtOH, dried and stored at $-18^{\circ} \mathrm{C}$ exhibited slightly lower desorption extend in PBS. It has to be outlined that these particles were almost entirely degraded after 150 min, and the solution was completely transparent after $48 \mathrm{~h}$, which proved the complete erosion of the microspheres. The highest registered extend of catechin release from Series 2 particles in PBS was $82.47 \%$ achieved after $48 \mathrm{~h}$ (Table 2 ). The mode of the in vitro release kinetics curve of Series 2 microparticles (Figure 2) resembles that of Series 1 particles. The initial "burst" release region accounted for $56 \%$ catechin desorption for a period of $190 \mathrm{~min}$ followed by a region of gradual release up to $48 \mathrm{~h}$. However, the value of $n>1$, determined by the Korsmeyer-Peppas model, which characterized with very high applicability, indicated super case II transport catechin in vitro release controlled by a complex of mechanisms: polymeric hydration, swelling-controlled release, erosion of non-swellable systems and diffusion [21].

The significant correlation between Series 2 experimental data and the zero-order model of the second release curve region evidenced constant catechin release for a period of approximately 44 hours (Figure 2). Similar biphasic sustained release profile results was observed in an in vitro release study from catechin-loaded polycaprolactone/polyvinyl alcohol microspheres [22] in PBS and from catechin-loaded 
Z. Yaneva, and D. Ivanova, Catechin hydrate desorption..., RAD Conf. Proc., vol. 4, 2020, 101-105

poly(l-lactide-co-glycolide) submicron-sized fibers [18] and nanoparticles [23] in PBS and in Britton-Robinson buffer. A release study combined with polymer degradation investigations outlined diffusioncontrolled mechanism of catechin release, which reported utmost degradation of the biopolymer carrier during the time span of catechin delivery [18].

Table 2. Kinetics of catechin hydrate in vitro release from Series 2 chitosan microparticles.

\begin{tabular}{lll}
\hline $\boldsymbol{t}, \mathbf{m i n}$ & $\begin{array}{l}\boldsymbol{C}_{\text {des }}, \\
\boldsymbol{\mu g} / \mathbf{m L}\end{array}$ & $\boldsymbol{E}, \boldsymbol{\%}$ \\
\hline 20 & 23.2 & 5.08 \\
\hline 60 & 63.0 & 13.79 \\
\hline 120 & 148.2 & 32.43 \\
\hline 190 & 256.1 & 56.04 \\
\hline 1440 & 320.5 & 70.13 \\
\hline 2880 & 376.9 & 82.47 \\
\hline
\end{tabular}

The conducted comparative analyses of the release efficiency of various catechin-loaded biopolymer micro-formulations presented in recent scientific studies and the results of the newly synthesized chitosan-based microparticles reported in the present study (Figure 4) proved undoubtedly the satisfactory release capacity of Series 1 and Series 2 biopolymer formulations and their capability of sustained catechin delivery in physiological medium.

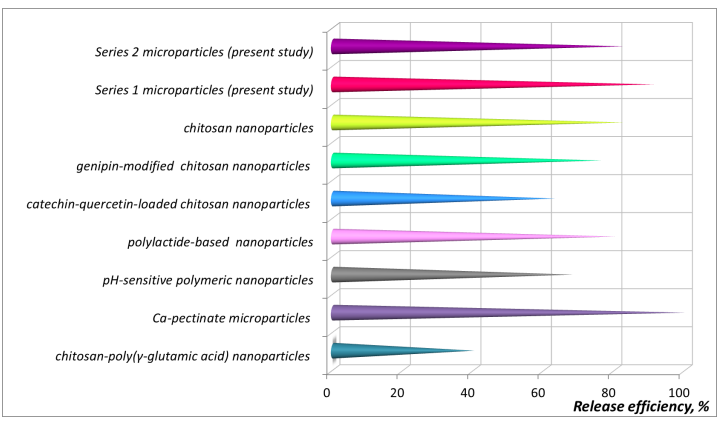

Figure 4. Comparative estimation of catechin release capacity of various biopolymer microcarriers [19, 24-28].

Zero-order release carriers could not only extend the circulation lifetime of polyphenol-loaded microparticles, but also maintain plasma bioflavonoid levels constant, and thus maximize their therapeutic efficacy and minimize toxic effects [20]. However, the design of zero-order release carriers, avoiding initial burst effects, still remains a big challenge for the scientific community. Thus, the results obtained in the present study outline prove the correct direction of the investigations; however, future experiments related to additional modification of the synthesis method to improve chitosan microparcticles structure and release behavior are necessary and outline the goals of the forthcoming studies of our scientific team.

\section{CONCLUSION}

The results obtained in the present study ascertained that catechin hydrate in vitro release from catechin-loaded chitosan microparticles, synthesized by a modified ion gelation method, was sustained in intestinal medium. Both types of particles were partially or fully degraded after $48 \mathrm{~h}$ and the highest release efficiency was within the range $82-91 \%$. Although an initial "burst" effect zone for both investigated systems was observed, the bioflavonoidcarrier systems attained zero-order release behavior during a prolonged time period until equilibrium establishment. The latter ensured the controlled release of the bioactive compound from the biopolymer microparticles in the intestine.

These results present valuable basis for future investigations on the applicability and efficiency of the synthesized chitosan-based microparticles as bioflavonoid carriers in pharmaceutics, food industry, veterinary and human medicine.

Acknowledgements: This work was supported by the Bulgarian Ministry of Education and Science under the National Research Programme "Healthy Foods for a Strong Bio-Economy and Quality of Life" approved by DCM \# 577/17.08.2018" and by Scientific Project 13/2018, FVM, Trakia University, Bulgaria.

\section{REFERENCES}

1. B. Liu, Y. Wang, Q. Yu, D. Li, F. Li, "Synthesis, characterization of catechin-loaded folate-conjugated chitosan nanoparticles and their anti-proliferative effect," CyTA - Journal of Food, vol. 16, no. 1, pp. 868-876, 2018. https://doi.org/10.1080/19476337.2018.1491625

2. S. Cosarca, C. Tanase, D.L. Muntean, "Therapeutic aspects of catechin and its derivatives - an update," $A B M J$, vol. 2, no. 1, pp. 21-29, Sept. 2019. https://doi.org/10.2478/abmj-2019-0003

3. M. Tzanova, V. Atanasov, Z. Yaneva, D. Ivanova T. Dinev, "Selectivity of current extraction techniques for flavonoids from plant materials," Processes, vol. 8, no. 10:1222, pp. 1-30, Oct. 2020. https://doi.org/10.3390/pr8101222

4. M. Ahmad, P. Mudgil, A. Gani, F. Hamed, F.A. Masood, S. Maqsood, "Nano-encapsulation of catechin in starch nanoparticles: Characterization, release behavior and bioactivity retention during simulated in-vitro digestion," Food Chemistry, vol. 270, pp. 95-104, Jan. 2019.

https://doi.org/10.1016/i.foodchem.2018.07.024

5. P. Paximada, A.A. Koutinas, I.G. Mandala, J.M. Lagaron, Y. Echegoyen, "Encapsulation of hydrophilic and lipophilized catechin into nanoparticles through emulsion electrospraying," Food Hydrocolloids., vol. 64, pp. 123-132, Mar. 2017. https://doi.org/10.1016/i.foodhyd.2016.11.003

6. A.M. Safer, S. Leporatti, J. Jose, M.S. Soliman, "Conjugation of EGCG and chitosan NPs as a novel nano-drug delivery system," Int. J. Nanomedicine, vol. 14, pp. 8033-8046, 2019. https://doi.org/10.2147/IJN.S217898

7. Z. Yaneva, D. Ivanova, N. Nikolova, M. Tzanova, "The $21^{\text {st }}$ century revival of chitosan in service to bio-organic chemistry," Biotechnology and Biotechnological Equipment, vol. 34, no. 1, pp. 221-237, 2020. https://doi.org/10.1080/13102818.2020.1731333

8. D.G. Ivanova, Z.L. Yaneva, "Antioxidant properties and redox-modulating activity of chitosan and its derivatives: biomaterials with application in cancer 
Z. Yaneva, and D. Ivanova, Catechin hydrate desorption..., RAD Conf. Proc., vol. 4, 2020, 101-105

therapy," Biores Open Access., vol. 9, no. 1, pp. 64-72, Mar. 2020.

http://doi.org/10.1089/biores.2019.0028

9. F. Li, H. Jin, J. Xiao, X. Yin, X. Liu, D. Li, Q. Huang, "The simultaneous loading of catechin and quercetin on chitosan-based nanoparticles as effective antioxidant and antibacterial agent," Food Res. Int., vol. 111, pp. 351-360, Sept. 2018. https://doi.org/10.1016/j.foodres.2018.05.038

10. C.L. Domínguez-Delgado, I.M. Rodríguez-Cruz, E. Fuentes-Prado, J.J. Escobar-Chávez, G. VidalRomero, L. García-González, R. I. Puente-Lee, "Drug carrier systems using chitosan for non-parenteral routes," in Pharmacology and Therapeutics, IntechOpen, Jul. 2014. https://doi.org/10.5772/57235

11. S. Potrč, T.K. Glaser, A. Vesel, N.P. Ulrih, L.F. Zemljič, "Two-Layer functional coatings of chitosan particles with embedded catechin and pomegranate extracts for potential active packaging," Polymers, vol. 12, no. 9: 1855, pp. 1-20, 2020. https://doi.org/10.3390/polym12091855

12. Z. Yaneva, N. Georgieva, "Physicochemical and morphological characterization of pharmaceutical nanocarriers and mathematical modeling of drug encapsulation/release mass transfer processes," in Nanoscale Fabrication, Optimization, Scale-up and Biological Aspects of Pharmaceutical Nanotechnology, $1^{\text {st }}$ Ed., Elsevier, 2018.

13. Z. Yaneva, N. Georgieva, M. Staleva, "Development of d,l- $\alpha$-tocopherol acetate/zeolite carrier system: equilibrium study," Monatshefte fur Chemie, vol. 147, no. 7, pp. 1167-1175, Mar. 2016. https://doi.org/10.1007/s00706-016-1714-x

14. Z. Yaneva, N. Georgieva, "Study on the Physical Chemistry, Equilibrium, and Kinetic Mechanism of Azure A Biosorption by Zea Mays Biomass," Journal of Dispersion Science and Technology, vol. 35, no. 2, pp. 193-204, Jan. 2014. https://doi.org/10.1080/01932691.2013.780242

15. Z. Yaneva, N.V. Georgieva, L.L. Bekirska, S. Lavrova, "Drug mass transfer mechanism, thermodynamics, and in vitro release kinetics of antioxidant-encapsulated zeolite microparticles as a drug carrier system," Chemical and Biochemical Engineering Quarterly $C A B E Q$, vol. 32, no. 3, pp. 281-298, 2018. https://doi.org/10.15255/CABEQ.2018.1319

16. Z. L. Yaneva, "Nonsteroidal anti-inflammatory drug solid-state microencapsulation on green activated carbon - Mass transfer and host-guest interactions," Chemical and Biochemical Engineering Quarterly, vol. 33, no. 2, pp. 249-269, 2019. https://doi.org/10.15255/CABEQ.2019.1656

17. Z. Yaneva, D. Ivanova, G. Beev, K. Besheva, "Quantification of catechin in Acacia catechu extract by non-derivative, first Derivative UV/Vis spectrophotometry and FT-IR spectroscopy," Bulgarian Chemical Communications, Special Issue D, vol. 52, 2020. - in press

18. P. Ghitescu, A. Popa, A. Schipanski, C. Hirsch, G. Yazgana, V.I. Popa, R.M. Rossi, K. Maniura-Weber, "Catechin loaded PLGA submicron-sized fibers reduce levels of reactive oxygen species induced by MWCNT in vitro," European Journal of Pharmaceutics and Biopharmaceutics, vol. 122, pp. 78-86, Jan. 2018. https://doi.org/10.1016/j.ejpb.2017.10.009
19. J.S. Lee, H.W. Kim, D. Chung, H.G. Lee, H.G., "Catechin-loaded calcium pectinate microparticles reinforced with liposome and hydroxypropylmethylcellulose: Optimization and in vivo antioxidant activity," Food Hydrocolloids, vol. 23, no. 8, pp. 2226-2233, Dec. 2009. https://doi.org/10.1016/j.foodhyd.2009.05.005

20. Y. Zhao, X. Xu, N. Wen, R. Song, Q. Meng, Y. Guan, S. Cheng, D. Cao, Y. Dong, J. Qie, K. Liu, Y. Zhang, "A drug carrier for sustained zero-order release of peptide therapeutics," Scientific Reports, vol. 7: 5524, pp. 1-9, Jul. 2017. https://doi.org/10.1038/s41598-017-0.5898-6

21. Y. Danyuo, C.J. Ani, A.A. Salifu, J.D. Obayemi, S Dozie-Nwachukwu, V.O. Obanawu, U.M. Akpan, O.S. Odusanya, M. Abade-Abugre, F. McBagonluri, W.O. Soboyejo, "Anomalous release kinetics of prodigiosin from poly-N-isopropyl-acrylamid based hydrogels for the treatment of triple negative breast cancer," Scientific Reports, vol. 9: 3862, pp. 1-14, Mar. 2019. https://doi.org/10.1038/s41598-019-39578-4

22. M. Sivabalan, V. Gayathri, C. Kiruthika, B. Madhan, "Formulation and evaluation of biodegradable polyphenolic microspheres for cancer," International Journal of Pharmacy \& Technology, vol. 4, no. 2, pp. 4493-4505, Jul. 2012.

Retrieved from:

https://www.ijptonline.com/wpcontent/uploads/2009/10/4493-4505.pdf

23. H. Pool, D. Quintanar, J. de Dios Figueroa, C.M. Mano, J.E.H. Bechara, L.A. Godínez, S. Mendoza, "Antioxidant effects of quercetin and catechin encapsulated into PLGA nanoparticles," Journal of Nanomaterials, vol. 2012, Article ID 145380, pp. 1-12, Sept. 2012. https://doi.org/10.1155/2012/145380

24. D.W. Tang, S.H. Yu, Y.C. Ho, B.Q. Huang, G.J. Tsai, H.Y. Hsieh, H.W. Sung, F.L. Mi, "Characterization of tea catechins-loaded nanoparticles prepared from chitosan and an edible polypeptide," Food Hydrocolloids, vol. 30, no. 1, pp. 33-41, Jan. 2013 https://doi.org/10.1016/j.foodhyd.2012.04.014

25. G. Zhang, J. Zhang, "Enhanced oral bioavailability of EGCG using pH-sensitive polymeric nanoparticles: characterization and in vivo investigation on nephrotic syndrome rats," Drug Design, Development and Therapy, vol. 12, pp. 2509-2518, Aug. 2018. https://doi.org/10.2147/DDDT.S172919

26. S. Mandal, K. Debnath, N.R. Jana, N.R.R. Jana, "Trehalose conjugated, catechin loaded polylactide nanoparticle for improved neuroprotection against intracellular polyglutamine aggregate," Biomacromolecules, vol. 21, no. 4, pp. 1578-1586, Apr. 2020. https://doi.org/10.1021/acs.biomac.oc00143

27. F. Li, H. Jin, J. Xiao, X. Yin, X. Liu, D. Li, Q., Huang, "The simultaneous loading of catechin and quercetin on chitosan-based nanoparticles as effective antioxidant and antibacterial agent," Food Research International, vol. 111, pp. 351-360, Sept. 2018. https://doi.org/10.1016/i.foodres.2018.05.038

28. R. Kaur, R. Rajput, P. Nag, S. Kumar, Rachana, M. Singh, "Synthesis, characterization and evaluation of antioxidant properties of catechin hydrate nanoparticles," Journal of Drug Delivery Science and Technology, vol. 39, pp. 398-407, Jun. 2017. https://doi.org/10.1016/j.jddst.2017.04.030 